\title{
Fluxos culturais e identitários: Consumo,
}

\section{POLÍTICA E HETEROTOPIA}

\author{
João Paulo Ocke de FREITAS* \\ Eu sou a mosca que pousou em sua sopa \\ Eu sou a mosca que pintou pra lhe abusar \\ (Raul Seixas, em "Mosca na sopa")
}

RESUMO: Este ensaio analisa os rolezinhos e o funk ostentação como movimentos protagonizados por jovens nas cidades e delineados principalmente a partir de 2013. É relevante problematizar a relação entre comunicação, cidade, cultura, alteridade e tecnologias, isto é, questionar instituições, símbolos e eventos ou fenômenos sociais que estão fortemente imbricados no desafio de legitimar a ocupação real e simbólica de espaços e a interlocução de atores diversos na cena urbana. Os rolezinhos e o funk ostentação são fluxos culturais e identitários que refletem o poder de sedução do mundo do consumo sem aderir a um projeto político no sentido estrito, mas capazes de se abrir para a política. Os rolezinhos e o funk ostentação canalizam percepções que metamorfoseiam os sentidos dos cenários heterotópicos da metrópole, ao mesmo tempo em que fortalecem o seu atributo de tecido comunicacional.

PALAVRAS-CHAVE: Rolezinhos. Funk ostentação. Eventos pós-periféricos. Legitimidade simbólica. Heterotopia.

\section{Introdução}

Entre 2003 e 2016, o Brasil atravessou momentos conturbados, nos quais não se destacaram apenas as "jornadas de junho" de 2013. No terreno da alta política, por exemplo, houve a ascensão do PT ao poder e a Ação Penal n 470 ("Mensalão"), no Supremo Tribunal Federal, instaurada em 2007 a partir de um inquérito de 2005 e cujo julgamento ocorreu em 2014. No ano de 2014 teve início a Operação Lava Jato e o ano de 2016 foi marcado pelo impeachment da presidente Dilma Rousseff.

\footnotetext{
* UFPE - Universidade Federal de Pernambuco. Campus Recife. Programa de Pós-Graduação em Ciência Política. Doutorando. Recife-PE, Brasil.50670-901. jp.ockedefreitas@gmail.com.

http://orcid.org/0000-0001-5172-1412.
} 
Diante disso, parece irrelevante analisar os rolezinhos e o funk ostentação. Ocorre que a matéria prima de todo esse contexto é feita de ingredientes diversos. Afinal, grandes e pequenos eventos podem ser reciprocamente esclarecedores.

Este artigo descortina uma reflexão acerca da relação entre a afirmação da identidade em meio ao desafio do reconhecimento de alteridades. A partir daí, busca-se compreender a articulação dinâmica entre os rolezinhos, o funk ostentação, a cidade, o mercado, as redes sociais e a ação política.

Interessa investigar a forma pela qual essas manifestações permitem iluminar a cidade como uma linguagem, em que podem ser reconhecidas diferenças de sotaque numa mesma base estruturante semântico-lexical, morfossintática ou de signos. Por fim, a conclusão encaminha uma discussão sobre as formas e os possíveis impactos reais e simbólicos da heterotopia contemporânea.

\section{Identidade e alteridade num contexto pós-periférico}

O Brasil se destacou, entre os anos 2003 e 2016, pela ascensão social e econômica de vasta parcela da população. Associada a isso, a difusão das redes sociais permitiu que os jovens protagonizassem um enredo urbano, conhecido como "rolezinho". Na trilha sonora dessa trama cênica, o funk ostentação marcou o compasso.

Por conseguinte, adotar, como ponto de partida, os fluxos culturais e identitários implica reconhecer a metrópole como locus de exercício de alteridades e de afirmação dinâmica de pluralidades cultuadas, aptas a se tornarem objetos metamorfoseáveis que atraem irresistivelmente o olhar. Os rolezinhos e o funk ostentação podem ser vistos como expressões de fluxos culturais e identitários e, portanto, podem também ser encarados como desafios para a afirmação da alteridade em sociedades ou espaços marcadamente desiguais, hierarquizados ou estratificados.

Trata-se de uma realidade, enfim, que não dispensa a controvérsia a respeito da tensão que tais movimentos promovem:

Aí vem a reação da Casa Grande, e a mídia em geral [...], colocando travas e controle na mobilidade urbana e no direito de ir e vir da juventude popular. A juventude negra e periférica vira uma "classe ameaçadora", que não é bem-vinda nos espaços de consumo da classe média branca. Ao estado de exceção e à violência contra os pobres se acrescenta uma polícia que reprime o funk e os rolezinhos. Essa incapacidade de entender as novas formas de sociabilidade e mobilidade dos jovens traz à cena o velho horror das classes populares e o 
apartheid racial, social e cultural. A ascensão social expôs a crise das cidades, a privatização dos espaços públicos e o desinvestimento nos equipamentos de lazer. $\mathrm{O}$ esquema de segurança dos shoppings, revistando e controlando os pobres, é a ostentação do fracasso do Estado e da sociedade na partilha da cidade. (BENTES, 2014, p.8).

Complementarmente, Barbosa-Pereira (2016) e Faria e Kopper (2017) advertem para os riscos do ímpeto classificatório que menospreza a possibilidade de ressignificação política de termos que carregam a pretensão de decifrar cabalmente os movimentos sociais e culturais:

a crítica do fenômeno descurou da própria dinâmica de apropriação e reapropriação de objetos, coisas e ideias na origem de uma compreensão nuançada dos rolezinhos como resultados de feixes de poder e nódulos de emaranhados entre o real das celebrações e o virtual de suas organizações (FARIA; KOPPER, 2017, p.258).

\section{O rolezinho como fluxo transbordante de tensões que aproximam e segregam}

De fato, simplificadamente, um fluxo cultural tende a carregar um volume simbólico que nem sempre pacifica ou harmoniza - pelo contrário, pode rivalizar com expectativas consagradas ou tornar a fruição cultural ruidosa e conflituosa. Tais ruídos e conflitos inclinam-se para ocorrer num planto interior, com os indivíduos confrontando seus próprios valores e expectativas com novas possibilidades interpretativas ou novos horizontes intelectuais e comportamentais.

Com efeito, a afirmação de identidades só pode se dar a partir do reconhecimento da alteridade num espaço determinado, marcado por uma história específica e constituído por múltiplas e complexas determinações (para lembrar o velho Marx). Isso serve para ressaltar que os fluxos identitários nunca ocorrem em espaços culturalmente neutros nem tampouco em espaços onde se esperam apenas reações predeterminadas ou imunes ao surpreendente e ao espanto do outro. Os fluxos culturais podem inovar e podem ser imprevisíveis.

Ora, os fluxos identitários necessariamente implicam um confronto: situação que deve ser entendida como um "estar de frente a", "fazer fronteira com", "estabelecer comparação entre"; e não só, pois que "confrontar" pode denotar o enfrentamento e a afronta. Afirmar a identidade demanda percorrer um arco de possibilidades que pode 
instrumentalizar desde a singela sedução até o uso da força física e pode promover o uso da razão ou do princípio da utilidade, a exclusão, a humilhação etc.

Tanto os questionamentos dirigidos contra o status quo como os assujeitamentos a esse mesmo status quo não devem ser vistos como efeitos de uma alienação promovida por um sujeito histórico unificado e coletivo, quer seja a "classe social" ou o "sistema" (qualquer que seja ele, incluindo-se aí a mídia). Por óbvio, "questionamentos" e "assujeitamentos" implicam uma relação: se há questionamentos, há algo ou alguém questionado por outro, assim como, se há assujeitamentos, há um ou mais de um autor do assujeitamento diante de um ou mais indivíduos assujeitados.

Ocorre que, numa sociedade altamente complexa, os indivíduos apresentam ou desenvolvem identidades múltiplas e até mesmo contraditórias, mutáveis e passageiras. São evidentes a multiplicação e a ampla capacidade de alcance das fontes de significação e de representação cultural que dialogam com os indivíduos, mas que a eles não se impõem linear ou unilateralmente e nem acriticamente. Por isso é que os questionamentos ou os assujeitamentos dos fluxos culturais e identitários devem ser vistos com base numa lógica que ultrapasse a abordagem baseada no conceito de classe ou na ideia de sistemas fechados.

Há que se considerar, então, que o conceito de "pós-periferia" evidentemente pressupõe o conceito de "periferia", sobre o qual se ergue um discurso em que, muitas vezes, ocorre a expressão de preconceitos e uma ênfase em aspectos que reforçam mecanismos de exclusão social. A "periferia” deixa de ser um mero conceito geográfico, comumente compreendida como região afastada do centro da cidade onde vive uma população de baixa renda, e assume uma conotação moral, decorrência da narrativa que caracteriza a periferia como o local da sujeira, da violência, da desordem, da licenciosidade e do escandaloso.

Uma cena ou contexto pós-periférico não implica a negação simbólica da periferia e nem a ideia de que não mais exista a periferia. Trata-se de um conceito que contempla as tensões, os hibridismos, os trânsitos complexos e variados de símbolos culturais próprios de intersticialidades fortemente midiatizadas. Não se trata, por conseguinte, de simplesmente valorizar os habitantes das periferias por serem minorias, mas de pôr em discussão a tensão entre imbricamentos e segregações que atingem os indivíduos da periferia nas cidades.

Assim, os rolezinhos não expressam uma rejeição radical, mas, sim, expressam uma tradução conveniente da periferia, integrando uma ação que tende para a busca de uma aceitação e uma valorização de seus atores (os rolezeiros) pela sociedade não periférica - há aí uma tentativa de demonstrar a capacidade de frequentar a sociedade não periférica por meio do consumo, do uso e da exibição de produtos caros e de 
etiquetas distintivas num dado espaço, o shopping-center, que é, por definição, um emblema do consumo. Como pontuam França e Dornelas (2014), os rolezeiros atuam coletivamente exteriorizando valores de matriz individualista e instrumentalizam o consumo como forma de exteriorizar a própria ascensão social, mas sem negar a sua “origem periférica".

Os rolezeiros querem demonstrar aptidão para atuar no cenário do shopping, por estarem devidamente equipados com os bens de consumo que são vendidos nas lojas do próprio shopping por eles frequentados. Curioso que muitos usam produtos falsificados, havendo aí também a reprodução da atitude de alguns membros da classe média que compram produtos "falsificados de alta qualidade" para uso próprio.

Os rolezinhos expandem fronteiras sociais, dissolvem espaços citadinos estratificados, dilatam as bordas de um campo cultural, midiático, social, estético e de consumo específico. Entretanto, não há um projeto prévio de implosão do "núcleo de algumas centralidades hegemônicas" (ROCHA; SILVA; PEREIRA, 2015, p.100). Não há, nos rolezinhos, qualquer projeto político definido para enfraquecer ou superar a "mercantilização da existência".

Em suma, para que, numa ação social, haja disputa pela hegemonia imagética e simbólica representativa de lugares sociais, há que se pressupor, pelo menos, o antagonismo entre dois projetos de natureza política, com organização mínima de pautas, programas, movimentos, um ideário de mudança que implique uma intervenção peculiar e sistemática no espaço social. Os rolezinhos, ainda que assumam a feição de uma ação com expressividade pública, não constituem uma prática política específica.

\section{O funk ostentação na dinâmica do habitus}

Nos fluxos culturais e identitários contemporâneos não há, efetivamente, um projeto de implosão das “centralidades hegemônicas". No que diz respeito, por exemplo, às mídias dominantes, vale lembrar que MC Guimê, um dos ídolos dos rolezeiros, teve a sua música "País do futebol" colocada na trilha de abertura da novela Geração Brasil, da Rede Globo, em 2014, ano de rolezinhos. Então, as próprias "estratégias midiáticas massivas de representação das outridades periféricas" (ROCHA; SILVA; PEREIRA, 2015, p. 100) são também ressignificadas ao incorporar, como mercadoria, alguns dos novos elementos culturais carregados pelas manifestações diaspóricas e polifônicas facilmente expandidas e propagadas pelas redes sociais a partir dos espaços tecnológicos colonizados pelos rolezeiros. 
Não é de hoje que existe a tensão entre uma suposta "cultura superior" e uma "cultura inferior" ou entre o "erudito" e o "popular". Também não é recente a incorporação de obras populares em composições do cânone erudito: pode-se observar esse procedimento em Brahms, que incorporou elementos ciganos húngaros às suas obras e ao seu estilo; em Villa-Lobos, que introduziu elementos das músicas indígena e africana às suas composições; ou em George Gershwin, que se deixou influenciar pelo jazz.

A "periferia" é objeto de interesse da cena musical há décadas - se, hoje, o samba é visto como manifestação genuína da cultura brasileira, no passado já foi visto como obra marginal de uma periferia povoada por "vadios". Dessa forma, o universo musical brasileiro já realizou reelaborações de assimetrias e pertencimentos desiguais, sendo que a fronteira entre o erudito e o popular vem sendo posta em questão há muito tempo, mas o debate sobre a validade dessa cisão não se encerrou e talvez não acabe, pois que talvez não haja solução possível (e nem tenha que haver):

[...] torna-se impossível uma cultura e uma comunicação desprovidas da influência dos media desinibidores. Alertamos: não se trata da defesa da bestialidade mediática e do obscurantismo da cultura. Ao contrário, defendemos que a gramática dos códigos culturais deve incorporar, de uma vez por todas, a importância de ferramentas que diferem do modo tradicional de educar o gosto. Manter o paradoxo não é o mesmo que manter a separação entre os dois media (inibidores e desinibidores), mas assumir sua dialogia, sua contradição e complementaridade. (GALENO; SILVA, 2015, p.12).

Note-se que no interior de cada nicho mercadológico, no plano musical, há segmentações interessantes, referentes a um "erudito superior" e a um "erudito inferior" (respectivamente, Brahms e Gershwin, por exemplo), um "popular sofisticado" e um "popular vulgar" (respectivamente, Chico Buarque e MC Boy do Charmes, por exemplo) e assim por diante. Esse tipo de segmentação ocorre no nicho do funk, em que há um "funk ostentação de raiz" em oposição a um "funk ostentação comercial" ou entre o "funk do bem" e o "funk do mal".

O "funk do bem", o que não exalta a criminalidade, é o mais consumido por todos. O "funk do mal", o que exalta a criminalidade, não constitui a expressão de uma "narcocultura brasileira" ou de uma convicção generalizada de que o crime é algo a ser valorizado ou que é um efetivo instrumento de transformação social. O funk ostentação expressa valores que podem ser aceitos ou rejeitados por determinados segmentos da população. Essa é uma posição compatível com a possibilidade aventada por Muniz 
(2016) de o funk ser dotado de um "capital existencial", com atributos para gerar valores e práticas compartilhados, decorrentes, portanto, de ações coletivas.

O mercado sempre classificou e segmentou produtos vendáveis. Resta aos consumidores dizer touché! e esperar as próximas "novas inovações" para serem devidamente incorporadas à velha lógica da acumulação: a sociedade, lembrando Cazuza, permanece diante de um futuro que repete o passado, construindo museus de grandes novidades, que serão, por sua vez, desmanchados no ar.

Segundo o blog [Periferia em movimento], o funk é, atualmente, um estilo musical que se divide em muitas vertentes. São citadas as do funk ostentação, a consciente, a sensual e a de apologia às drogas e à violência. A cada uma dessas vertentes, corresponde um estilo de apresentação visual, um modo de falar distintivo e uma gramática própria, semelhantes entre si, mas diferenciados em relação a outros movimentos culturais e sociais que, no segmento jovem da população, estão sempre profundamente ligados à fruição identitária e performática de gêneros musicais. (ROCHA; SILVA; PEREIRA, 2015, p.105).

O consumo e o sucesso exaltados no funk ostentação são produtos de uma adesão improvisada da periferia a um estilo de vida de classe média alta e elitizado, que implicam a afirmação de um desejo de inclusão numa dinâmica que já existe para segmentos privilegiados da população. Nesse sentido, não há paradoxos com potencial político de ruptura ou de reivindicações - há apenas a tentativa de imitar, aderir sem questionar e sem um objetivo manifesto de revolucionar, ou seja, há muito mais uma adesão inquieta, ansiosa e "selvagem" ao capitalismo do que uma tentativa de influenciar explícita ou implicitamente os rumos do "capitalismo selvagem".

Todo o movimento representado pelo funk não implica uma tentativa consciente e elaborada de grupos organizados para alterar a conduta ou as formas de ação do governo, da classe média ou da elite; pelo contrário, implica uma introjeção não conflituosa e mediada pelo mercado dos valores dessas classes por uma parte da população da periferia. Nas festas da periferia, ocorre a passagem, sem tensões existenciais ou morais, do tom sério de algumas letras para o tom leve de outras, tendose em vista apenas o potencial de divertimento das músicas:

[...] muitos rappers aderiram ao "ostentação", sendo que, nos shows de funk da atualidade, escuta-se também músicas de grupos como Racionais MC, ícones do rap político. O que esse fato parece lembrar é que esses referenciais musicais se confundem na escuta dos jovens que vão aos shows e que cantam e consomem essas músicas, uma vez que, em ambos os casos, o que surge para eles é o potencial 
de afirmação e autoestima da periferia pela via musical, seja num tom mais sério e contestador, seja num tom de entretenimento e de leveza que os carros luxuosos, as marcas de roupas, os óculos, os relógios parecem querer trazer para a presença cotidiana. (ROCHA; SILVA; PEREIRA, 2015, p.108).

Por isso, é válido recuperar o conceito de habitus nas formulações de Norbert Elias (1994b) e Pierre Bourdieu (2002), por força do seu poder de clarificar a vitalidade disposicional dos indivíduos envolvidos em interações sociais múltiplas e dispersas. A partir dessas formulações, importa assimilar a tensão entre passado e presente, expectativas individuais e disposições sociais, tendência para a constância e tendência para a volubilidade.

De acordo com Norbert Elias (1994a), elucidar a interação do indivíduo e da sociedade implica considerar como as pessoas entendem a si mesmas diante do processo histórico e do caldo cultural em que as subjetividades específicas se constituem e são definidas. Daí decorre o conceito de habitus, que Elias (1994b) desenvolve para definir a "economia psíquica" dos indivíduos a partir da modernidade.

Sem incompatibilidades irredutíveis com o conceito de Elias (1994b), Bourdieu (2002) pormenoriza o conceito de habitus, mas ressalve-se que, como demonstram Catani et al (2017), o conceito de habitus na sua obra não é uniforme e sofreu reelaborações. Ainda assim, de acordo com Bourdieu (2002), o habitus expressa dinâmicas sociais e de relações de poder instáveis, historicamente e espacialmente situadas, livres de condicionamentos lineares e uniformes, e é desvinculado de processos de racionalização subjetiva. Traduz, a bem dizer, uma gama articulada de inclinações espontâneas, modelado por experiências acumuladas, constitui um filtro por meio do qual os indivíduos se inserem nas múltiplas atividades sociais e conformam um específico "estilo de vida". O passado do indivíduo compõe o repertório que configura o habitus e lhe dá o suporte para interagir socialmente, de forma mutável, com a história presente: o "estilo de vida" não é fixo nem é fruto de uma estratégia linear predefinida.

O habitus expressa um sistema aberto em que se manifestam expectativas, atitudes e tendências que a indústria cultural não ignora. A indústria cultural já se apropriou do funk como entretenimento vendável, presente em muitos programas da mídia hegemônica. Considere-se, além disso, que as classes altas criam, a todo o momento, marcas de distinção social, habitus ou estilos de vida dentre os quais se encontra o consumo do funk, visto como entretenimento produzido numa realidade exótica, ou seja: a classe alta coopta o funk como elemento de divertimento e exercício narcisista do seu próprio poder de sedução. Assim é que permanece nítida a separação dos habitus e padrões de vida das classes sociais, mas sob novas formas. 
Nesse contexto, é inegável a força das mídias sociais, mobilizadas por uma massa de pessoas com enorme capacidade de exercício criativo e de imaginação independente e original. Essas mídias têm sido, inclusive, capazes de pautar o discurso midiático hegemônico que não tem o poder de exercer, por meio de estratégias unilaterais, uma sempre eficaz persuasão manipulativa sobre a população, que, por sua vez, não deve ser vista como uma mera massa mamulenga:

A cidade não é uma TV com seus programas e apresentadores ávidos por audiências eleitorais. Nem sua administração é uma ilha de edição que transforma seus habitantes em meros espectadores-eleitores. Mas como se trata de uma visibilidade permeada pelo paradoxo, não advogamos apenas uma possibilidade negativa dos media desinibidores. Se pensarmos, sobretudo, com o advento da internet e seus usos e espacialidades novas, a carta paradigmática herdeira do velho Humanismo torna-se limitada. Denominamos este novo habitar de um duplo movimento. Por um lado, vivenciamos a espacialidade indoors da qual fazem parte a relação entre espaços da casa e ou da intimidade e os espaços dos computadores e outros dispositivos comunicacionais; por outro lado, há a espacialidade outdoors que é mediada pela exibição das e pelas ferramentas mediáticas, sobretudo, smartphones, TVs e pela própria rua. As redes sociais e seus adeptos são verdadeiras ágoras on-line de si mesmos (GALENO; SILVA, 2015, p.10).

\section{A web como fator de ressignificação do cenário urbano... E a política com isso?}

A web medeia as espacialidades polissêmicas e eleva a capacidade de imaginação e de intervenção dos sujeitos nos espaços urbanos. Diante dessa nova "carta paradigmática" é admissível perguntar, de um lado, qual o locus do mainstream? E, de outro lado, qual o locus do underground ou do afetado mundo hipster? Cabe perguntar, sim, qual é o discurso hegemônico? E qual é o discurso contra-hegemônico?

Certamente o mercado ainda exerce um relevante papel na definição desses loci, mas dada a fluidez da comunicação por meio das mídias digitais, o mercado tende a acompanhar e não apenas a liderar a definição de estilos, modos e modas. Não por outro motivo, a imprensa tradicional está em vias de extinção ou está passando por transformações radicais, e várias publicações de grandes editoras ou estão sendo suprimidas ou radicalmente modificadas.

Nesse contexto é que se impõe a autonomia da imaginação criativa diante do poder da mídia: 
O apelo que as mídias fazem ao simbólico, ao imaginário, leva-os a transitar num reino em que as manipulações têm acesso restrito e apresentam resultado incerto. A amplidão de "leituras" que uma mesma imagem possibilita para uma mesma pessoa é o que configura a polissemia das imagens. Por isso, os esforços para "domesticar" o imaginário em parte dão certo, e em parte, naufragam, soçobram. A criatividade é fundamental para a obtenção da autonomia moral porque a imaginação é a condição da escolha, da decisão. Sem ela, é apenas possível seguir a regra, obedecer. O imaginário é o cerne da autonomia e da recuperação da dimensão humana porque a imagem é religante (por contágio emocional e por recurso a múltiplos simbolismos) e são constantes os retornos regulares da cultura às ideias imaginais. $\mathrm{O}$ sonho, terreno do imaginário, é indissociável do pensamento e do questionamento dos poderes. Sonhar é essencial para todos os animais, embora somente os homens sonhem acordados. E esse sonho só existe porque há uma parte dele mesmo que nunca se convence (COSTA, 2015, p.33-34).

A web é um importante veículo para o metamorfoseamento dos sentidos dos cenários urbanos. A territorialidade delimitada do shopping foi, assim, ressignificada na medida em que novos atores passaram a circular nele de uma forma imprevista, carregando novos elementos culturais, provenientes de campos específicos, que mudaram a relação do shopping com a região da cidade à qual está ligado e com os seus frequentadores habituais. As dinâmicas top-down de significação foram postas em xeque e passaram a encarar o desafio de naturalizar os rolezinhos (para absorver os seus atores como consumidores disciplinados) ou de esperar para ver se os rolezinhos seriam mais um modismo efêmero.

O fato é que dinâmicas bottom-up de significação implicam a associação de elementos simples para assumir progressivamente, através de acréscimos de elementos e de novas associações, maiores proporções num sistema dado, sem negar, portanto, o sistema maior ao qual essas dinâmicas se integram, ainda que se manifeste de forma ruidosa ou imprevista. De fato, os rolezinhos não negaram radicalmente as dinâmicas top-down de significação, porque efetivamente incorporaram elementos do sistema de consumo de massa, utilizaram os recursos tecnológicos (negociados pelo mercado) e constituíram espaços digitais (legitimados pelo mesmo mercado) para mediar a integração à lógica do consumo, da celebridade e do entretenimento. Dessa forma, a mídia é instrumentalizada pelos rolezeiros.

A síntese dessas manifestações pode apropriadamente ser a seguinte:

Será que estes o fazem para afirmar uma forma de autonomia que transita pendularmente pelo coletivismo autogestionário, pelo anarquismo pós-midiático 
e, outras vezes, pelas searas do narcisismo e do culto a super-eus, bens agora não mais exclusivos dos "bem-nascidos"? O consumo, atravessado por processos de midiatização do social, participa ativamente da repercussão alcançada por acontecimentos pós-periféricos, fenômenos de lastro "glocal", para lembrar o termo popularizado por Armand Mattelard. Todos querem se divertir. Muitos querem protestar. A polifonia daí resultante não é linear. Não propriamente revolucionária. Não necessariamente reacionária. (ROCHA; SILVA; PEREIRA, 2015, p.102).

Então, é admissível avaliar se a imagem que o shopping quer transmitir para o seu público consumidor pode e deve ser compatibilizada com as imagens produzidas pelos rolezinhos; afinal, o shopping passa a ser um "ator convidado" do próprio rolezinho, também protagonizando o entretenimento, juntamente com os rolezeiros. Em outras palavras, diante da cena posta, há que se dar voz ao shopping para que se manifeste e atue no confronto de imagens, de símbolos e de valores.

Nesse contexto, resta saber quais serão os parâmetros de atuação ou o roteiro para a ação, de tal forma que a violência simbólica, material e física não seja também protagonista. Isso porque, entre protagonistas, é comum a briga de egos: há, de fato, uma disputa em que o shopping quer assegurar uma determinada imagem para o mercado e em que os rolezeiros querem transmitir a imagem de que estão perfeitamente incluídos nesse mesmo mercado.

Se não há propriamente um conflito político, deve-se reconhecer que o campo delicado da política se impõe, já que os princípios que norteiam e definem o funcionamento e as condições de existência do espaço privado podem ser confrontados pelos interesses e valores de segmentos sociais específicos. Ao buscarem visibilidade, sujeitos sociais tendem a assumir o confronto como um elemento de seu desejo de serem visíveis; e quanto mais autônomos e ativos forem, menos propensos estão a acatar ordens ou orientações que venham de instâncias externas ao próprio grupo do qual fazem parte.

Diante disso, é preciso relativizar a ideia de que as diásporas pós-periféricas manifestam em muitos jovens a afirmação da individualidade em estilos próprios e marcadamente distintivos. A identidade do eu é construída num processo com múltiplas vinculações e numa relação necessária de atração por grupos determinados que implicam adesões estéticas e comportamentais devidamente apropriadas pelo mercado e por este segmentadas nas prateleiras das "variedades de mercadorias" para serem livremente escolhidas e consumidas. 
Como as chamadas "diásporas pós-periféricas" são uma ação de grupos mais (ou menos) organizados, principalmente por meio das mídias sociais, deve-se considerar que tais grupos são rotulados e a eles é atribuída uma marca (que, inclusive, define um objeto de pesquisa facilmente identificável). Há, assim, uma diferenciação em relação a outros grupos que preenchem o espaço urbano.

Nada impedia que o rolezinho viesse a se tornar uma marca e que o funk ostentação se mercantilizasse para o consumo de segmentos específicos da sociedade. No final, ocorreu o de sempre: o próprio mercado estimulou a imitação para incrementar o consumo e promover "diferenciações homogeneizadas ou estandardizadas".

\section{À guisa de conclusão: a facticidade estupefata diante do shopping como heterotopia}

Ao analisar o conceito de habitus na obra de Bourdieu, Catani et al (2017, p.216) afirmam que a "prova do pudim teórico do habitus deve consistir em comê-lo empiricamente". Ora, tal asserção implica relacionar o rolezinho e o funk ostentação, diante dos cenários heterotópicos. Sobretudo, porque, no horizonte dos enfoques de Elias e Bourdieu, encontra-se a formação do gosto, as práticas de consumo ou as escolhas de bens materiais e culturais que permitem definir "estilos diferenciadores" (exteriorizados pelos indivíduos, mas compartilhados pelos membros de mesmas classes sociais, grupos ou linhagens).

Por conseguinte, cabe considerar o rolezinho e o funk ostentação como expressões sociais que conferem peculiaridade à metrópole comunicacional, já que ela pode ser considerada um ambiente possível para que essas manifestações ocorram, seja através de um momento ou uma cena, seja, ainda, através de uma trilha sonora. Isso é particularmente revelador no que tange aos shoppings, cenário e tema do funk ostentação.

Tal consideração pode ser sustentada com base nos termos postos pelo método da facticidade estupefata, tal como desenvolvido por Canevacci (2008), o que implica a percepção de que o espaço urbano pode ser eficazmente metamorfoseado em inovações dissonantes de sentido, transcendendo as lógicas binárias e os monismos universalistas. Dessa forma, por exemplo, é que se destacam sujeitos aptos a visualizar o shopping e a sua carga poderosa de fantasia de consumo como um fetiche que realça o sex appeal do inorgânico numa facticidade estupefata, não paralisada, mas, sim, móvel, inesperada e assombrada. 
Ora, o shopping, quando é apropriado pelos rolezinhos e quando tem o seu conteúdo exaltado pelo funk ostentação, torna-se um objeto fluido do fetichismo visual venerado pelos sujeitos das diásporas pós-periféricas. Com base nisso, o shopping pode ser visto como uma heterotopia, apesar de assim não ter sido considerado expressamente por Foucault (2013) na conferência pronunciada em 1967.

Desde os anos 1960 até a década de 2010, o shopping assumiu o lugar real, efetivo, bem inscrito no mercado, oposto às utopias, mas ao mesmo tempo delas reflexo, como num espelho. O shopping pode ser visto como um contraespaço, o locus da utopia, um lugar real fora de todos os lugares. Se, para Foucault, o museu e a biblioteca são heterotopias próprias à modernidade, por motivos semelhantes, o shopping bem pode assumir esse papel:

[...] as heterotopias são frequentemente ligadas a recortes singulares do tempo [...] De modo geral, em uma sociedade como a nossa, pode-se dizer que há heterotopias que são heterotopias do tempo quando ele se acumula ao infinito: os museus e as bibliotecas, por exemplo. Nos séculos XVII e XVIII, os museus e as bibliotecas eram instituições singulares; eram a expressão do gosto de cada um. Em contrapartida, a ideia de tudo acumular, a ideia de, em certo sentido, parar o tempo, ou antes, deixá-lo depositar-se ao infinito em certo espaço privilegiado, a ideia de constituir o arquivo geral de uma cultura, a vontade de encerrar todos os tempos em um lugar, todas as épocas, todas as formas e todos os gostos, a ideia de constituir um espaço de todos os tempos, como se este próprio espaço pudesse estar definitivamente fora do tempo, essa é uma ideia totalmente moderna [...] (FOUCAULT, 2013, p.25).

Tal como o papel das heterotopias pode variar em função do contexto em que se encontram, o shopping tem a sua concepção cartesiana desafiada pelo rolezinho: partindo de Foucault (2013), pode-se afirmar que o espaço é ressignificado, é metamorfoseado ao dar vazão a questionamentos a respeito de outros espaços sociais, na medida em que os seus objetos reais encaminham fantasias de consumo e também na medida em que constitui um espaço onde se criam ilusões que denunciam o restante do mundo real como ilusão.

E não só: antes visto pelos sujeitos das dinâmicas periféricas como espaço de um "outro" elitizado e alienado da realidade, o shopping, quando tomado pelos rolezinhos, passa a ser visto pelos seus antigos frequentadores como espaço dos novos protagonistas pós-periféricos, igualmente vistos como iludidos diante do mundo real. A heterotopia é ressignificada. A metrópole continuamente comunica valores, inclusive os que giram em torno das manhas e das birras do mercado - afinal, os jovens das diásporas 
pós-periféricas não heterotopizam os cenários do espaço urbano de forma unilateral. $\mathrm{O}$ funk ostentação, inclusive, serve para reforçar o papel de espelho a refletir a farra do mercado e contribui para compor uma heterotopia crônica, ao modo da festa:

O teatro, seguramente, mas também as feiras, estes maravilhosos sítios vazios à margem das cidades, por vezes mesmo no centro delas e que se povoam uma ou duas vezes por ano com barracas, exposições, objetos heteróclitos, lutadores, mulheres-serpentes e profetisas de boa fortuna. (FOUCAULT, 2013, p.25).

Está claro que o "ritual de entrada" é subvertido pelos rolezinhos, mas outros rituais vão sendo estabelecidos e novas trilhas vão pontuando a encenação das massas pós-periféricas em ação no palco do consumo. Além disso, há que se reconhecer que a heterotopia implica uma tensão entre a possibilidade do isolamento e da porosidade e, dessa forma, o shopping é um espaço aberto que também exclui: "Todo mundo pode entrar, mas, na verdade, uma vez que se entrou, percebe-se tratar-se de uma ilusão e que se entrou em parte alguma. A heterotopia é um livro aberto que tem, contudo, a propriedade de nos manter de fora" (FOUCAULT, 2013, p.27) - é bom não esquecer que o olhar do outro e o aparato de segurança podem ter a pretensão de excluir.

É assim: como uma mosca fatídica e indefectível, o shopping heterotópico do mundo mítico e real do consumo, metamorfoseado pela web e pelos fluxos culturais e identitários, permanece pousado na sopa política que as metrópoles se tornaram.

\section{Cultural and IDENTIty flows: Consumption, POLICY and HETEROTOPIA}

ABSTRACT: This essay analyzes the rolezinhos and ostentation funk as movements carried out by young people in the cities and outlined mainly from 2013 on. It is relevant to problematize the relationship between communication, city, culture, otherness and technologies, that is, to question institutions, symbols and social events or phenomena which are strongly involved in the challenge of legitimizing the real and symbolic occupation of spaces and the interlocution of diverse actors in the urban scene. The rolezinhos and ostentation funk are cultural and identity flows which reflect the seductive power of the consumer world without adhering to a political project in the strict sense, but capable of opening themselves to politics. The rolezinhos and the ostentation funk channel perceptions which metamorphose the senses of the heterotopic scenarios of the metropolis, while they strengthen its attribute of communicational fabric. 
KEYWORDS: Rolezinhos. Ostentation funk. Post-peripheral events. Symbolic legitimacy. Heterotopia.

\section{Flujos culturales E DE IDENTIDAD: Consumo, POLÍtica Y HETEROTOPIA}

RESUMEN: Este ensayo analiza los pequeños rolezinhos y la ostentación funk como movimientos liderados por jóvenes en las ciudades y perfilados principalmente a partir de 2013. Es pertinente problematizar la relación entre comunicación, ciudad, cultura, alteridad y tecnologías, es decir, cuestionar las instituciones, los símbolos y los acontecimientos o fenómenos sociales que están fuertemente imbricados en el desafio de legitimar la ocupación real y simbólica de los espacios y la interlocución de los diversos actores de la escena urbana. Los rolezinhos y el funk ostentación son flujos culturales y de identidad que reflejan el poder seductor del mundo del consumo sin adherirse a un proyecto político en sentido estricto, pero capaz de abrirse a la política. Los rolezinhos y el funk ostentación canalizan percepciones que metamorfosean los sentidos de los escenarios heterotópicos de la metrópoli, a la vez que refuerzan su atributo de tejido de comunicación.

PALABRAS CLAVE: Rolezinhos. Funk ostentación. Eventos posperiféricos. Legitimidad simbólica. Heterotopía.

\section{Agradecimento}

O presente trabalho foi realizado com apoio da Coordenação de Aperfeiçoamento de Pessoal de Nível Superior - Brasil (CAPES) - Código de Financiamento 001.

\section{REFERÊNCIAS}

BARBOSA-PEREIRA, Alexandre. Os "rolezinhos" nos centros comerciais de São Paulo: juventude, medo e preconceito. Revista Latinoamericana de Ciencias Sociales, Niñez y Juventud, Colômbia: Centro de Estudios Avanzados en Niñez y Juventud del Cinde; Universidad de Manizales, v. 14, n. 1, p.545-557, 2016.

BENTES, Ivana. Respeitosamente vândala. Entrevistador: Eduardo Nunomura. Cult, São Paulo: Bregantini, p.7-10, mar. 2014. 
BOURDIEU, Pierre. Esboço de uma teoria da prática, precedido de três estudos de etnologia cabila. Oeiras, Portugal: Celta, 2002.

CANEVACCI, Massimo. Fetichismos visuais: corpos erópticos e metrópole comunicacional. São Paulo: Ateliê, 2008.

CATANI, Afrânio Mendes et al (Orgs.). Vocabulário Bourdieu. Belo Horizonte: Autêntica, 2017.

COSTA, Josimey. A palavra sobreposta: imagens contemporâneas da Segunda Guerra em Natal. 2. ed. Natal-RN: EDUFRN, 2015.

ELIAS, Norbert. A sociedade dos indivíduos. Rio de Janeiro: Zahar, 1994a.

ELIAS, Norbert. O processo civilizador. Rio de Janeiro: Zahar, 1994b. 2v.

FARIA, Louise Scoz Pasteur de; KOPPER, Moisés. Os rolezinhos e as metamorfoses do urbano no Brasil. Anuário Antropológico, Brasília: UnB, v. 42, n. 2, p.239-266, 2017. Disponível em: https://journals.openedition.org/aa/2286. Acesso em: 24 jan. 2020.

FOUCAULT, Michel. O corpo utópico, as heterotopias. São Paulo: n-1, 2013.

FRANÇA, Vera; DORNELAS, Raquel. No bonde da ostentação: o que os "rolezinhos" estão dizendo sobre os valores e a sociabilidade da juventude brasileira? Revista Ecopós, Rio de Janeiro: UFRJ, v. 17, n. 3, p.1-13, 2014.

GALENO, Alex; SILVA, Josimey Costa da. Massas cênicas e consumo: estetização política e visibilidades singulares do habitar a cidade. Congresso Internacional em Comunicação e Consumo. São Paulo: PPGCOM ESPM, out. 2015. Disponível em: http://anaiscomunicon2015.espm.br/GTs/GT5/14_GT05_GALENO_SILVA.pdf. Acesso em: 17 jul. 2019.

MUNIZ, Bruno Barboza. Quem precisa de cultura? O capital existencial do funk e a conveniência da cultura. Sociol. Antropol., Rio de Janeiro, v. 6, n. 2, p. 447-467, 2016. Disponível em: http://www.scielo.br/scielo.php?script=sci_arttext\&pid=S223838752016000200447\&lng=en\&nrm=iso. Acesso em: 24 jan. 2020.

ROCHA, Rose de Melo; SILVA, Josimey Costa; PEREIRA, Simone Luci. Imaginários de uma outra diáspora: consumo, urbanidade e acontecimentos pós-periféricos. Galáxia, São Paulo, n. 30, p.99-111, dez. 2015.

Recebido em 17/07/2019.

Aprovado em 29/07/2020. 